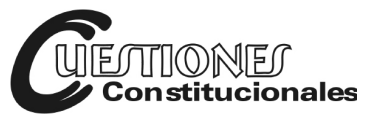

Revista Mexicana de Derecho Constitucional

Núm. 32, enero-junio 2015

\title{
COMENTARIO A LA LEY GENERAL DE LOS DERECHOS DE NIÑAS, NIÑOS Y ADOLESCENTES
}

\author{
Fabiola Edith PÉrez ÁlVAREZ*
}

\section{HACIA UNA GARANTÍA INTEGRAL DE LOS DERECHOS DE NIÑAS, NIÑOS Y ADOLESCENTES EN MÉXICO}

Con la ratificación del Senado de la República el 21 de septiembre de 1990 de la Convención sobre los Derechos del Niño, ${ }^{1}$ se adquirió el compromiso de adoptar todas las medidas administrativas, legislativas y de otra índole para dar efectividad a los derechos reconocidos en dicho instrumento internacional.

Desde entonces, se han realizado diversas adecuaciones al marco jurídico nacional con el objetivo de armonizar el derecho interno con las disposiciones y principios de la Convención y sus protocolos facultativos, así como con las observaciones generales y recomendaciones específicas del Comité de los Derechos del Niño.

En esta tarea destacan las reformas de 2011 a los artículos 4o. y 73 de la Constitución Política. ${ }^{2}$ La primera incorporó el principio del interés superior de la niñez y la mención de que éste deberá guiar el diseño, ejecución, seguimiento y evaluación de las políticas públicas dirigidas a la infancia. La segunda, atribuyó al Congreso la facultad de expedir leyes que establecieran la concurrencia de la Federación, los estados, el Distrito Federal y los municipios, en el ámbito de sus respectivas competencias, en materia

Doctoranda en el posgrado de derecho de la UNAM, con sede en el Instituto de Investigaciones Jurídicas.

1 Publicado en el Diario Oficial de la Federación (DOF) el 25 de enero de 1991.

2 Publicado en el $D O F$ el 12 de octubre de 2011. 
de derechos de niñas, niños y adolescentes, velando en todo momento por su interés superior y cumpliendo con los tratados internacionales de la materia, de los que México es Estado parte.

En este contexto, el 1o. de septiembre del año en curso, el Ejecutivo federal presentó con carácter de trámite preferente, la Iniciativa de Ley General para la Protección de Niñas, Niños y Adolescentes. Dicha Iniciativa fue ampliamente debatida por los legisladores y enriquecida con las aportaciones de organizaciones de la sociedad civil, especialistas, académicos, organismos autónomos de protección de derechos humanos y organismos internacionales.

Finalmente, el pasado 4 de diciembre de 2014 se publicó en el Diario Oficial de la Federación, el decreto que expide la Ley General de los Derechos de Niñas, Niños y Adolescentes, y que reforma diversas disposiciones de la Ley General de Prestación de Servicios para la Atención, Cuidado y Desarrollo Integral Infantil.

Esta Ley constituye un avance legislativo muy significativo en la materia, ya que establece estándares normativos generales con el objetivo de garantizar de manera integral los derechos humanos de cuarenta millones de niñas, niños y adolescentes en el país. A continuación se abordan algunos aspectos previstos en la actual Ley, que pueden contribuir a dar efectividad a los derechos de este colectivo.

\section{ENFOQUE GARANTISTA DE DERECHOS HUMANOS}

Primeramente, y en concordancia con el modelo de la protección integral, la Ley contempla como objeto de protección los derechos de niñas, niños y adolescentes, y no a sus destinatarios. En este sentido, se les reconoce como titulares plenos de un amplio catálogo de derechos, de conformidad con los principios de universalidad, interdependencia, indivisibilidad y progresividad y demás contemplados en la Ley, en los términos que establecen los artículos 1o. y 4o. de la Constitución Política.

Asimismo, establece una cultura de respeto, promoción y protección de los derechos de niñas, niños y adolescentes, basada en los principios rectores de la Ley, los cuales deberán guiar las acciones de los órganos jurisdiccionales, las autoridades administrativas y los órganos legislativos.

Particularmente, se señala que el principio del interés superior tendrá consideración primordial en las cuestiones que involucren niñas, niños y 
adolescentes. Por lo tanto, al presentarse diferentes interpretaciones se elegirá la que satisfaga de manera más efectiva este principio rector. Asimismo, y con la finalidad de salvaguardar el interés superior y las garantías procesales de aquéllas, se deberán evaluar y ponderar las posibles repercusiones en la toma de decisiones que les afecten en lo individual o colectivo.

Lo anterior constituye una adecuación a la más reciente Observación General del Comité de los Derechos del Niño, en la cual se subraya que el interés superior del niño es un concepto tridimensional, a saber: a) un derecho sustantivo, b) un principio jurídico interpretativo fundamental, y c) una norma de procedimiento. ${ }^{3}$ Esto implicará una evaluación y determinación de este principio en términos de procesos administrativos, de presupuesto, de elaboración de políticas públicas y en todos los casos que involucren a niñas, niños y adolescentes.

\section{REDISEÑO INSTITUCIONAL}

Destaca la creación del Sistema Nacional de Protección Integral de los Derechos de Niñas, Niños y Adolescentes como instancia encargada de establecer instrumentos, políticas, procedimientos, servicios y acciones de garantía y protección de los derechos de este grupo poblacional.

Tiene como eje la coordinación de las atribuciones de la Federación, las entidades federativas, los municipios y las demarcaciones territoriales del Distrito Federal. Por tanto, deberá asegurar su colaboración en la formulación, ejecución e instrumentación de políticas, programas, estrategias y acciones en materia de protección y ejercicio de los derechos de este colectivo.

Con el establecimiento del Sistema Nacional de Protección Integral, se establece una estructura de coordinación para la protección, prevención y restitución integral los derechos de niñas, niños y adolescentes, a la vez que se garantiza la visibilidad de sus derechos en los diferentes niveles de gobierno, así como en los sectores público, social y privado.

El Sistema Nacional de Protección Integral tiene una vinculación al más alto nivel ejecutivo, al estar presidido por el presidente de la República. Con ello, se fortalece y garantiza la transversalidad de las políticas públicas

3 Observación General núm. 14 sobre el Derecho del Niño a que su Interés Superior sea una Consideración Primordial (art. 3, párr. 1), Organización de las Naciones Unidas, 2013, párr. 6 . 
en la materia, a la vez que denota el carácter primordial que para el Estado mexicano tienen los derechos de niñas, niños y adolescentes.

Para la operatividad del Sistema Nacional de Protección Integral, se establece un órgano administrativo desconcentrado de la Secretaría de Gobernación, para ejercer las funciones de secretaría ejecutiva. Este órgano funge como instancia de interlocución con organizaciones de la sociedad civil, con la academia y con demás instituciones de los sectores social y privado.

Sobresalen dentro de sus atribuciones las de coordinación de las acciones entre las dependencias y las entidades competentes de la administración pública federal que derivan de la Ley; la elaboración del anteproyecto del Programa Nacional, el seguimiento y monitoreo de la ejecución del Programa Nacional y la realización de estudios e investigaciones para fortalecer las acciones en favor de la atención, defensa y protección de niñas, niños y adolescentes.

Por otra parte, se fortalece al Sistema Nacional para el Desarrollo Integral de la Familia y se le atribuye la protección de los derechos de niñas, niños y adolescentes cuando los mismos se encuentren restringidos o vulnerados; en este sentido, es un sistema de protección especial. Asimismo, se estipula que la institucionalización procederá como último recurso y por el menor tiempo posible, priorizando las opciones de cuidado en un entorno familiar.

Igualmente, el Sistema Nacional para el Desarrollo Integral de la Familia será responsable de promover la formación, capacitación y profesionalización del personal de instituciones vinculadas con la protección y restitución de los derechos de niñas, niños y adolescentes. Este aspecto resulta particularmente importante frente a nueva estructura jurídica, institucional y de políticas públicas para garantizar integralmente los derechos de este sector poblacional.

Al interior de la estructura del Sistema Nacional para el Desarrollo Integral de la Familia, la Federación y, en consecuencia, las entidades federativas, deberán contar con procuradurías de protección, que tendrán como objetivo la protección integral de los derechos de niñas, niños y adolescentes; en este sentido, es un sistema de protección general.

Para tal efecto, se dispone que la protección integral deberá abarcar como mínimo: atención médica y psicológica, seguimiento a las actividades académicas, y entorno social y cultural, y la inclusión de quienes ejerzan la patria potestad, tutela o guarda y custodia de niñas, niños y adolescentes en las medidas de rehabilitación y asistencia. 


\section{FORTALECIMIENTO DE LOS ORGANISMOS AUTÓNOMOS DE PROTECCIÓN DE DERECHOS HUMANOS}

En la Observación General núm. 2, el Comité de los Derechos del Niño señala que las instituciones nacionales independientes de derechos humanos representan un importante mecanismo para promover y asegurar la aplicación de la Convención sobre los Derechos del Niño, así como la realización universal de los derechos de niñas, niños y adolescentes. ${ }^{4}$

La reforma al artículo 102, apartado B, de la Constitución Política, ${ }^{5}$ incrementó el impacto de los organismos de protección de los derechos humanos al estipular la obligación de todo servidor público de dar respuesta a sus recomendaciones $\mathrm{y}$, en su caso, fundar, motivar y hacer pública su negativa. Adicionalmente, se estableció la facultad de investigar hechos que constituyan violaciones graves de derechos humanos, y se amplió su competencia al conocimiento de asuntos laborales.

La Ley General dispone que la Comisión Nacional de los Derechos Humanos y los organismos de protección de los derechos humanos de las entidades federativas, en el ámbito de sus competencias, deban establecer áreas especializadas para la protección efectiva, observancia, promoción, estudio y divulgación de los derechos de niñas, niños y adolescentes.

Lo anterior complementa la reestructura institucional establecida en la Ley General, ya que implicará una vigilancia independiente del cumplimiento de las obligaciones contraídas no sólo por virtud de la Ley, sino por la Convención sobre los Derechos del Niño, sus protocolos facultativos y demás tratados internacionales en los que México es Estado parte. Igualmente, conllevará un monitoreo y evaluación constante de los progresos logrados en la implementación de las políticas públicas en la materia y en la realización plena de los derechos de niñas, niños y adolescentes.

\section{ESTRATEGIA NACIONAL}

El Comité de los Derechos del Niño señala que para la promoción y respeto de los derechos de niñas, niños y adolescentes en los Estados partes, la

4 Observación General núm. 2 sobre el Papel de las Instituciones Nacionales Independientes de Derechos Humanos, Organización de las Naciones Unidas, 2002, párr. 1.

5 Publicado en el DOF el 10 de junio de 2011. 
administración pública en su conjunto y en todos sus niveles debe trabajar sobre la base de una estrategia nacional unificadora, amplia, fundada en los derechos y basada en la Convención. ${ }^{6}$

La Ley General contempla la elaboración de dicha estrategia nacional traducida en un programa nacional a favor de niñas, niños y adolescentes. Para tal efecto, se estipula que las autoridades federales, de las entidades federativas, municipales y de las demarcaciones territoriales del Distrito Federal, en el ámbito de sus respectivas competencias, así como los sectores privado y social, a través del Sistema Nacional de Protección Integral, participarán en su elaboración y ejecución, el cual deberá ser acorde con el Plan Nacional de Desarrollo y con la Ley General.

El Programa Nacional contendrá las políticas, objetivos, estrategias y líneas de acción prioritarias en materia de ejercicio, respeto, promoción y protección integral de niñas, niños y adolescentes. Asimismo, dispone la inclusión de mecanismos transparentes que permitan su evaluación y seguimiento, así como de participación ciudadana.

En cuanto a la formulación del Programa Nacional, será importante desarrollar un proceso sostenible destinado a dar efectividad a los derechos de este colectivo, fijar objetivos reales y asequibles en relación con el catálogo de derechos económicos, sociales, culturales, civiles y políticos de que son titulares niñas, niños y adolescentes, y la previsión de los recursos necesarios, tanto humanos como financieros, que permitan dar cumplimiento a los mismos.

Al respecto, la Ley General atribuye al Sistema Nacional de Protección Integral la promoción del establecimiento de presupuestos destinados a la protección de los derechos de niñas, niños y adolescentes en los tres órdenes de gobierno. En este aspecto es imprescindible adoptar una estrategia transversal, con el propósito de obtener un panorama integral que garantice sus derechos y de contribuir al fortalecimiento de la transparencia y la rendición de cuentas.

\section{SiSTEMA DE EVALUACIÓN Y DIAGNÓSTICO}

La eficacia de las políticas públicas depende en gran medida de su adecuada evaluación y diagnóstico por parte de una institución autónoma y ajena

6 Observación General núm. 2 sobre el Papel de las Instituciones Nacionales Independientes de Derechos Humanos, Organización de las Naciones Unidas, 2002, párr. 25. 
al Sistema Nacional de Protección Integral. En este contexto, y en atención a la reciente adición del apartado C del artículo 26 de la Constitución, ${ }^{7}$ se establece a cargo del Consejo Nacional de Evaluación de la Política de Desarrollo Social la evaluación de las políticas de desarrollo social vinculadas con la protección de los derechos de niñas, niños y adolescentes. De acuerdo con los resultados de las evaluaciones, el Consejo emitirá las sugerencias y recomendaciones que considere pertinentes al Sistema Nacional de Protección Integral.

La labor del Consejo Nacional de Evaluación de la Política de Desarrollo Social resultará fundamental, ya que la viabilidad de los planes, programas y acciones para garantizar los derechos de niñas, niños y adolescentes dependerá en la medida que se pueda contar con un referente evaluativo, que permita controlar el avance sistemático en el logro de los objetivos y metas establecidos.

\section{SISTEMA DE INFORMACIÓN}

La reunión de datos suficientes y fiables sobre la situación de niñas, niños y adolescentes constituye una de las medidas generales de aplicación de la Convención sobre los Derechos del Niño. ${ }^{8}$ En el caso de México, el Comité de los Derechos del Niño manifestó en varias ocasiones su preocupación frente a la ausencia de un sistema de reunión de datos que permitiera analizar la situación de los derechos de niñas, niños y adolescentes en el país. ${ }^{9}$

Frente a este panorama, se atribuye al Sistema Nacional de Protección Integral la obligación de conformar un sistema de información a nivel nacional, con el objetivo de contar con datos desagregados que permitan monitorear los progresos alcanzados en el cumplimiento de los derechos de niñas, niños y adolescentes en el país, incluyendo indicadores cualitativos y cuantitativos.

El establecimiento de un sistema de información en el país resultaba indispensable tanto para valorar los progresos en la implementación de

7 Publicado en el DOF el 10 de febrero de 2014.

8 Observación General núm. 5 sobre las Medidas Generales de Aplicación de la Convención sobre los Derechos del Niño, Organización de las Naciones Unidas, 2003, párr. 48.

9 Observación Final al III Informe de México sobre Niñez, Comité de los Derechos del Niño, 42o. Periodo de Sesiones, 2006, párr. 13. 
políticas públicas en la materia como para identificar los problemas existentes y determinar discriminaciones en la realización de los derechos de niñas, niños y adolescentes.

\section{REFLEXIONES FINALES}

Con la ratificación de la Convención sobre los Derechos del Niño, el Estado mexicano ha realizado importantes esfuerzos a favor de los derechos de niñas, niños y adolescentes. Sin embargo, la falta de un marco general con un enfoque integral de garantía de derechos humanos, la ausencia de mecanismos de coordinación y evaluación para garantizar los derechos de este sector poblacional y la inexistencia de un sistema de información y recopilación de datos constituían serios obstáculos para asegurar el cumplimiento efectivo de los derechos de niñas, niños y adolescentes.

En un primer acercamiento, la Ley General de los Derechos de Niñas, Niños y Adolescentes contiene elementos que podrían permitir a México transitar hacia una nueva realidad y estructura que garantice los derechos humanos de niñas, niños y adolescentes de forma integral y coordinada. 